\section{WIDOWHOOD, LEISURE ACTIVITY ENGAGEMENT, AND COGNITIVE FUNCTION AMONG OLDER ADULTS}

Y. Lee ${ }^{1}$, I. Chi ${ }^{2}$, L. Palinkas 2 , 1. Helen Bader School of Social Welfare, University of Wisconsin-Milwankee, 2. University of Southern California

Maintaining cognitive function is an essential aspect of successful aging. Widowhood is a salient life transition that can affect older adults' cognitive function. Leisure engagement has received increasing attention because it is still modifiable in later life to help prevent cognitive decline. Nonetheless, limited longitudinal studies have examined how widowhood influences cognitive function, and even fewer studies have tested the role of leisure activities in this relationship. Thus, this study delineated the mechanism of widowhood, leisure activity engagement, and cognitive function among older adults using a national longitudinal dataset, the Health and Retirement Study, and its supplementary dataset, the Consumption and Activities Mail Survey, which repeatedly measured individuals' leisure activity engagement. Findings showed no significant association between widowhood and cognitive function during a 4-year period. However, engagement in mental activities moderated the impact of widowhood on cognitive function. Specifically, the benefit of mental activity engagement on cognition was more pronounced among individuals who were recently widowed compared to those who were married. This implies a protective role of mental activities in the relationship between widowhood and cognitive function. This suggests the need for interventions with mentally stimulating activities at the community level to retain cognition among individuals in early phase widowhood. Future studies are necessary to explore whether other factors such as changes in physical and mental health and intergenerational support from adult children during widowhood may further influence this mechanism among widowhood, leisure activities, and cognitive function.

\section{COGNITIVE FUNCTIONING IN OLDER ADULTS: A LIFE SPAN HEALTH PRODUCTION FUNCTION APPROACH}

\section{N.B. Ferdows, Brown University}

Life-course theory postulates that our ultimate health outcomes are, in part, a response to an accumulation of advantages and disadvantages that begin early in life. Using 2012 Health and Retirement Study data on 9,221 older adults, we quantify how childhood factors contribute to "cognitive achievement", directly and indirectly through their effects on mediating adult outcomes. We estimate "cognitive achievement" as the output of a production function, produced by childhood health and socioeconomic-status, adult socioeconomic achievements, health habits and pertinent demographics, adopting simultaneous equations mediation model to quantify the direct and indirect effects of childhood factors. We find that favorable childhood conditions significantly improve cognitive achievement, both directly and indirectly, mediated through education, income, and wealth. Our findings complement available research by showing that cognitive achievement is a function of childhood, adult and later-life factors. The pathways from childhood factors to cognitive achievement, however, could be more complex than previously reported.

\section{SESSION 915 (SYMPOSIUM)}

INTEREST GROUP SESSION - REMINISCENCE, LIFE STORY, AND NARRATIVE: PEDAGOGICAL STRATEGIES FOR TEACHING AND ENGAGING STUDENTS IN REMINISCENCE AND LIFE REVIEW WORK

Chair: M.B. Ligon, York College of Pennsylvania, York, Pennsylvania

Co-Chair: L. Yancura, University of Hawai i at Manoa, Honalulu, Hawaii

Discussant: A. Kris, Fairfield University, Westport,

Connecticut

In order to find purpose and meaning in the lived experience, we are often called to reflect, review, and reminisce. Congruent with this year's conference theme, "The Purposes of Longer Lives," this symposium highlights five paper presentations focusing on practical, tested, pedagogical strategies that can be used when engaging students and teaching methods of reminiscence and life review work with elders. Important ethical considerations of this type of work will also be addressed. The first presentation describes practical strategies for implementing an oral history project with undergraduate students and underscores the positive outcomes this project can have for students and elders alike. The second presentation describes Therapeutic Narrative Intervention (TNI) and the importance of elucidating variations of motives, goals, and techniques associated with TNI for students. The third presentation highlights positive outcomes associated with inclusion of a life review project in a baccalaureate nursing course as educators seek to increase student interest in working with older adults. The fourth presentation explores a hybrid instructional method consisting of ethnodrama and transformative learning approaches through analysis of oral history transcripts. The final presentation describes basic ethical principles developed within the context of research with human subjects and focuses on how these principles can be adapted for student-based reminiscence projects. While reminiscence and life review work takes many forms, these presentations highlight the benefits of inclusion of such activities in the classroom.

\section{CONNECTING THE GENERATIONS: A PRACTICAL GUIDE TO IMPLEMENTING AN ORAL HISTORY PROJECT IN THE GERONTOLOGY CLASSROOM}

M.C. Ehlman 1 , M.B. Ligon, $\mathrm{PhD}^{2}$, G. Moriello, $\mathrm{PhD}^{3}, 1$. University of Southern Indiana, Evansville, Indiana, United States, 2. York College of Pennsylvania, York, PA, U.S.A., 3. Utica College, Utica, NY, U.S.A.

Experiential learning is an important theme in education today. Including an intergenerational oral history project in undergraduate gerontology courses is a pedagogical approach that can have positive outcomes for students and elders alike. In this practice article, authors draw from personal experience as they describe an oral history project which they have conducted for over a decade. Key findings from this project include that students' attitudes toward older adults and the aging process improve both when the project is included in a traditional classroom or in an on-line environment. There are equivalent positive shifts in students' attitudes when they 